\title{
The Aesthetics of Story-telling as a Technology of the Plausible
}

\author{
Esther Eidinow (Nottingham) and Rafael Ramirez (Oxford)
}

\begin{abstract}
In this paper we argue that that which philosophers consider as being included in the domain of the aesthetic is a crucial aspect determining the plausibility of a narrative; that plausibility actually plays a more significant role than probability in many cognitive processes of deliberation and decision making; and that the aesthetics of story-telling is a technology of the plausible.

We offer two case-studies, one an ancient account of deliberation and decision making, the other from a modern newspaper article, to illustrate our argument that the aesthetic is an essential element in various stages of the process of decision making, from determining what needs to be decided, through identifying the basis for decision making, to the act of decision making itself. In that context, we highlight the role of the aesthetic in the framing of future possibilities in the process of scenario planning.
\end{abstract}

In conclusion, we propose that focusing on the aesthetics of story-telling as a technology to create and share plausibility is a useful way to analyse scenario stories in scenario-planning work; we hope that it may be a useful concept with which to develop further research in this area.

\section{Introduction}

In November 2013, the Spanish Economics Minister, Luis de Guindos, attempted to halt the appointment of José María Roldán as President of the Spanish Banking Association (AEB), which represents all commercial banks in the country. The reason given was that, at the time, Roldán was still heading the Financial Regulation and Stability Department at the Bank of Spain. De Guindos' objection was not worded as having to do with a conflict of interest or put forth on ethical grounds. Instead, noting that Roldán, "a person who until very recently has participated in the preparation of the financial rules that have led to a crisis and a ransom of 40,000 million (euros)",... would now "paid by the taxpayer,...remain in a senior accountability position in the sector", the Minister argued that this change from regulator to the regulated sector was not "estético - it was not "aesthetic" (de Barrón, 2013). Why would a minister of economics in one of the countries that was most strongly hit by the global financial crisis say that the issue he had with this appointment was "(un)aesthetic"?

This curious choice of terms did not go unnoticed at the time; in fact, it prompted 95 on-line comments posted within 48 hours on the website of the daily newspaper El País, mostly making fun of his choice. A year later, in November 2014 - as we started writing this paper over 690,000 items appeared when one Googled the original El País headline "Guindos expresa a la banca su 'malestar' con su nuevo president" (or "Guindos expresses his malaise regarding the new president to the banking sector"). Many of these were comments suggesting that Guindo's own "aesthetics" were also to be questioned, including those involved in his having himself moved from investment banker to minister. In the end, the Minister's views had little effect: Roldán was unanimously elected to the position for an 
initial four-year term - so although De Guindos found his behaviour ugly, not enough people shared his perspective. This event illustrates the central point for our investigation in this paper, which argues for the importance of developing a better understanding of the creation of plausible arguments, and, specifically, the role of the aesthetic in the generation of plausibility.

The core of our argument rests on the proposition that that which philosophers consider to be included in the domain of "the aesthetic" is a crucial aspect determining the plausibility of a narrative - and this matters insofar as plausibility may play a more significant role than probability in many cognitive processes of deliberation and decision making (Selin and Pereira, 2013 and Selin, 2011, with regard specifically to scenario planning). Here, we focus on the role of "the aesthetic" in the framing of future possibilities (cf. Judge, 1991), and suggest that achieving aesthetic excellence in stories enables scenario planners to excel at conveying plausible futures and the insights these hold to decision-makers in ways that are helpful to them in their framing of decision possibilities (Cornelissen \& Werner, 2014; Ramirez \& Wilkinson, 2016).

We describe the aesthetics of story-telling as a "technology" of plausibility. This may not be self-evident to futures scholars unfamiliar with social and technology studies (STS), but to those that are, it appears natural to consider a story (particularly if it has been written or recorded or is retold repeatedly) as a "frozen" insight and knowledge, accumulated over time, which can be used in different contexts, again and again, to enable sense giving and sensemaking (as Weick, 1995; 60-61). Latour (e.g., 2002) and other STS scholars have looked at how technologies encapsulate human action, freeze it, and make it available in contexts other than the one in which it arose. As Hutchins (1995) found in studying navigators in the South seas, technologies enable practices, and their successful use enables practitioner excellence. We stress that this technology can be wielded in a number of different ways, and suggest that this idea may be a fruitful concept for further research, opening up insights into how plausibility is generated, manifested, shared, used, and valued.

The aesthetics of story-telling and story-sharing is, in fact, a very widespread and longrunning technology. Across cultures, humans employ narratives to make sense of events and experiences in the world around them, to share and test them with others with whom they might need to address the challenges and to exploit the opportunities these entail. Stories are not only factual descriptions, they manifest and convey implicit knowledge and are thus inescapably also experienced in aesthetic terms, expressing and conveying considerations of what "feels right". It may be that the ubiquity of this technology has paradoxically made it and the roles it plays less visible - and seem less salient - than it deserves to be. This technology complements other technologies of the plausible, such as causal maps and graphic system diagrams (Wilkinson \& Ramirez, 2016). We can compare it to pencils and paper perhaps: while the technology is very widespread and well accepted, it is rarely considered as a technology, precisely because it has become so very common. Like pencils and paper, the ubiquity and wide use of this technology of story-telling means it no longer requires a user manual: people (particularly in oral societies, but also in literate ones using writing and reading extensively) grow up with this technology. But in this paper, we propose to bring it back into view, to foreground it, and to explore it by delving into how it plays a role in shaping and co-producing the plausibility of a story in ways that makes the story useful in decision making and strategy (see Wilkinson, 2009). There is a huge literature on studies of strategy as narrative, of organisations as narratives, and of futures in terms of narrative (recent examples from this journal include Milojević and Inayatullah, 2015 and Raven and 
Elahi, 2015). We acknowledge but do not marshal these important literatures in this paper, which concentrates instead on the role of the aesthetics of story-telling as a technology of the plausible. Below we present first our understanding of aesthetics, then of plausibility; we examine the relationship between the two, and how aesthetics in stories can be understood as a technology of plausibility; finally, we illustrate our argument with two case studies.

\section{What is aesthetics? ${ }^{1}$}

Philosophy explores how we experience and perceive, how we conceive and understand and order, how we know ourselves and the world(s) we inhabit and bring about, and how all of these are inter-related. The study of aesthetics in philosophy deals with those understandings, perceptions, conceptions, and experiences that we qualify (often after the fact) with adjectives such as 'beautiful', "ugly", "elegant", or "repulsive". Aesthetic knowledge is considered to depend largely on sensing and feeling, on empathy and intuition, and on critically examining how we relate conception to perception, without as well as with words: it offers "sensory knowing versus intellectual/propositional knowing” (Taylor \& Hansen, 2005).

There is growing evidence from cognitive psychology and neurobiology (Damasio, 2000) that aesthetic forms of knowing precede other forms, and shape how these other forms of knowing operate. This had already been proposed by philosophers such as Cassirer (1964) and Langer (1942). If so, the pattern recognition involved in sense perception and the forming of ideas, precedes the formalisation of these into concepts and their manifestation as words. Thus in mathematics "the motivational aesthetic does not merely catch the mathematician's attention, rather it serves the necessary role of framing the very way problems and initial conjectures are identified" (Sinclair, 2004, 277). And in analyzing modernity and comparing his views to Beck's and Giddens', Lash concluded that: "Well before the post-traditional society of the past two decades, the first instantiation of reflexive modernity was through the aesthetic" $(1994,212)$.

As this cognitive analysis suggests, whether and how someone finds some (particular) thing "beautiful" or "ugly" is subjective depending on taste, and this aspect can vary according to one's situation before, during and at the time of an experience. But culture, or rather cultures, play a particularly important role in shaping those perspectives. As Bourdieu (1979) noted, different cultures shape what groups and the individuals in them consider in aesthetic terms (e.g. opera, soccer, nature, etc.). Thus, for the field of law, Schlagg proposed that: "Law is an aesthetic enterprise. Before the ethical dreams and political ambitions ... can even be articulated ... aesthetics have already shaped the medium within which those projects...work" (Schlagg, 2002, 1049). He reported that if a judge's work is premised upon an aesthetic where justice is organised as pigeonhole categories, she will first consider in which category the case fits; whereas if the aesthetic of the law she uses instead is justice as a field of forces, consideration will be given to the forces and counterforces that exert themselves upon the case and to which the case will contribute. Thus, the "same" case would be treated very differently, depending on the aesthetic that is at play - more often than not, implicitly and unquestioned.

In this paper we fully acknowledge cultural differences (as will be seen from our case studies) but we are Kantian in the sense that we consider aesthetics to be a universal characteristic of mindful activity, which plays out in each culture in its own culturally

\footnotetext{
${ }^{1}$ This section draws in part from Ramirez (2005).
} 
determined way. But either framing still leaves the question of exactly how and why aesthetics can achieve this - what knowledge is it that aesthetics conveys and how does this become a basis for judgment? The answer we find most persuasive is to frame aesthetics in terms of connection (Sandelands, 1998 and Taylor and Hansen, 2005): that is, as shared forms or systems that allow individuals to express their sense of relationality. Aesthetic responses shape our judgments, and these are informed by a combination of personal, subjective experiences, informed by shared cultural frames, and shaped by and expressing relationality within our culture. As a result, we conclude that aesthetics in stories can be regarded as a technology in the sense of Latour (1990): a technology that creates the plausible.

\section{What is "plausibility"?}

Bosch $(2010,387)$ offers a succinct characterisation to answer the question posed in our subheading: a theory can be accepted as plausible when it is "in accordance with (practical) empirical findings; subjective/intersubjective ideas, thoughts, and feelings; and the opinions of and cultural categories used by others". In attempting to define plausibility, it may help briefly to look at its close but confusing relationship to the construct of probability. We note that, in the field of scenario planning specifically, defining this relationship is an ongoing challenge: "Attempts to clarify the general methodological confusion about scenario practices - practices which encompass probable, plausible or possible futures - is already evident" (Wilkinson, 2009: 110). The key word in this passage is "attempts": as of 2009; there was no clear resolution. Indeed, Ramírez and Selin (2014) found that scholars in scenario planning who argued for either "plausibility" or "probability" as their preferred approach to creating persuasive futures often overlooked the potency of the "other" approach.

Ramírez and Selin (2014) surveyed, more generally, the long history of confusion relating these terms to each other. They found that a distinction between them began to be developed at the end of the seventeenth century, when, most notably thanks to Locke, probability was established as inference when insufficient experiential evidence was available in scientific pursuits. In contrast, plausibility from its very beginning lent itself to what today is called "spin"; one of its earliest meanings is "the disposition to approve" (1558; see the Oxford English Dictionary; s.v. "Plausibility"). An examination of its uses over time (ibid.) indicates how, in the eighteenth century, the meaning of each term became more distinct, as probability became something served and even defined by mathematical calculus and took a central role in statistics, while plausibility continued in its original sense of providing "the appearance of believability and credibility". But this developing distinction became blurred when Bayes brought subjectivity into probability, also in the eighteenth century: as Ramírez and Selin (2014) observed; "Bayesian probability" denotes a degree of belief considered to be objective and rational. It moves the meaning of probability beyond "the relative frequency of occurrence of an outcome in given conditions..." and re-confuses probability and plausibility with each other. For followers of Bayes, probability measures belief; whereas plausibility simply proposes it. Although metrics seem to matter much more to measures of probability than impressions of plausibility, they are not; as we will see below, sufficient to be compelling.

The relations between probability and plausibility remains a source of debate in scientific inquiry: although Meckler and Baillie $(2003,276)$ proposed that the usefulness provided by 
scientific method was precisely the move from plausibility to the more calculable probability, Bosch argued that, in practice, plausibility is a better assessment of truth within a constructivist epistemology. Indeed, away from the world of theory, in arenas where these questions are played out in real-time, there is little disagreement on the core importance of plausibility in producing a convincing argument. As John Kay argued in the Financial Times ( Kay, 2013), in a legal setting, a good (in the sense of "plausible") story "balances probabilities" in the eyes of the court, and may help to render someone guilty or innocent in a way that probability as percentage of being right cannot do. Remember, it was plausibility ("plausible deniability") that was used by the Reagan administration to conceal how much the US president really knew about the Iran - Contra affair (Cheit, undated).

These observations may be supported by arguments the authors have made to the effect that practical wisdom/judgment (phronesis) has an important aesthetic element ( Eidinow \& Ramirez, 2012). They have argued that this interpretation is supported by research on types of deliberation conducted within organisations: the use of aesthetics as a heuristic tool for clarifying cognitive processes now extends across a wide range of research; examples include the analysis of organizations ( Ramirez, 1987, Ramirez, 1991 and Ramirez, 1996) and how people in them behave and understand them (Strati, 1999); urban policy - and how it is enacted (Floyd, 1983); management of forests (Gobster, 1999); decision making at NASA and how it comes to be ineffective (Feldman 2000); the selection of personnel at service firms (Warhurst, Nickson, Witz, \& Cullen, 2000); the evaluation of formulae in theoretical physics (Farmelo, 2002); and the preferences of managers in selecting modes of business innovation (Ramírez \& Arvidsson, 2005).

For the purposes of this paper, it is important to draw attention to what these arguments suggest about the role of cultural frameworks in the perception of plausibility, which allows us to build a link between plausibility and aesthetics. If shared cultural knowledge informs our sense of plausibility, this, we argue, is informed by the relationality created by a shared aesthetic: thus, crafting the aesthetic (pleasing or not) becomes a technology of the plausible.

Some understanding of how a plausible or "good" story may be developed has been examined by Wilkinson and Ramírez (2010), who proposed that one thing that makes plausibility unique and uniquely helpful is that it has to be co-constructed in conversation. Thus, what person A considers plausible to start with may not convince person B, who queries how that first plausibility [P1] could actually come to be. Person A reflects on this criticism, and accepts that some qualification is needed to persuade $\mathrm{B}$ of the plausibility of what he or she has said. After reviewing P1 in light of person B's criticisms, person A issues a second revised version $\mathrm{P} 1.1$ - this process may continue until person A convinces person $\mathrm{B}$, and both agree that version P1.n is plausible, and take it to person C. The process may then be repeated, further versions developed, in light of objections, and finally P2 is released. In this sense, the process of revising a story draft to enhance its plausibility may be compared with a process of debugging software from the "beta" version to one that is good enough to be released to potential users.

This process helps us to envision something of the way in which story-telling is a collaborative process, which resonates with van der Heijden's (2005) idea of the art of "strategic conversation" used in strategic planning, and the link between strategic conversation and the development of new, unique, shared insights. However, the process described above comes across as primarily intellectual, and it rather takes for granted the nature of plausibility. As we have suggested, the creation of plausibility, and the judgment 
that a narrative possesses plausibility (i.e., how we determine that a story is itself plausible), depends not only on our intellectual capabilities, but also on the aesthetic each of us, individually or in groups, has developed, which is a result of our cultural frames and sense of relationality. We note here how the process of co-creating a story may actualise that sense of relationality, thus enhancing the sense of plausibility. In the next section, we illustrate these processes with two examples, one ancient and one modern.

\section{Case studies, ancient and modern}

\subsection{Riddles from Delphi}

Our first example involves a story by the ancient historian, Herodotus (7.139-143) concerning one of the Athenian responses to the invasion by an army led by King Xerxes in the early fifth century. Herodotus reports that the Athenians sent an embassy to the oracular sanctuary at Delphi to consult the priestess there, the so-called "Pythia". While possessed by the god Apollo, this priestess would provide answers to the questions posed by consultants, and tradition indicates that these were given in the form of riddling verses, which the consultant must resolve. The veracity of this process is debated by scholars who propose that, in fact, the answers were likely to have been more straightforward ("yes" or "no" responses, or cult instructions), while the more elaborate responses were the result of later literary elaboration (see for example, Bowden, 2005, esp. 34; cf. Maurizio, 1995). But whichever historical interpretation is preferred, it can be argued that oracular consultation demonstrates the role of aesthetics in decision making, revealing the ways in which knowledge may be based not on intellectual judgment, but rather on a felt sense of "what is right", which depends on a specific cultural framework.

In his story Herodotus recounts that the Athenian ambassadors approached the Pythia and, to begin with, received a response that was horrifying: it told them to go home immediately, conveying a message that the Athenians must evacuate their city, which would be burned, while its temples ran with blood. The ambassadors were upset by the message from the oracle and felt hopeless, but then they were advised to make a second consultation. The response they received this second time was slightly more appealing: it appeared to tell them to retreat, it warned them that they would lose much of what they now owned, but to "trust in their wooden walls", and that Salamis would be a location that would "bring death to women's sons." They wrote it down, and took it back to Athens... And there, a huge debate took place: some argued that the "wooden wall" meant the thorn hedge that had once surrounded the Acropolis; others that it meant the Athenian navy. In the end, we are told by Herodotus, the general Themistocles led the way towards the development of an interpretation that most felt they could support. The chresmologues (professional oracle interpreters) had interpreted the "wooden walls" as meaning the Athenian fleet, but stated that this meant an Athenian defeat. The general Themistocles, in contrast, argued that Salamis would mark the location of a Persian defeat. Herodotus notes for us how the Athenians perceived his interpretation as, literally, something "more to be chosen" (as Eidinow, 2013). Themistocles' version of the oracle persuaded them that Delphi was telling them to prepare to do battle at sea. The majority of Athenians followed this strategy - and, in brief, in the battle of Salamis they led the Greeks to victory over the Persians.

This historical account provides a useful overview of a process of deliberation in which aesthetics plays a key role in shaping judgments of plausibility and decision making. The first consultation by the Athenians produced a story about the future that the Athenians found all- 
too plausible: they were presented with a completed narrative, which confirmed their worst fears. Significantly, the messengers were unwilling to carry this message back to the city because it was so bad, not because they felt it was wrong or they did not understand it; indeed, it was very clear and must have seemed highly probable, aligning with their intellectual understanding of the current situation. In contrast, the second consultation was more complex: its riddling form demanded a resolution that would satisfy everyone. It came during a process of debate, in which, as a community, the Athenians reframed their decision to remain. Here again we have to examine the basis for their judgment: it was not that they thought that Themistocles was intellectually accurate; rather, according to Herodotus, it was because his interpretation allowed them to behave bravely, putting up a fight against the invaders, rather than running away. Thus, the Athenians interpreted the riddle according to their shared aesthetic sense of what was "right", which included a strong, shared understanding of Athenian identity.

\subsection{Riddles from Florida}

The second story brings us back to the present, and concerns two incompatible views on the future of one of the wealthiest parts of the United States - Miami Beach. One view is dire, and is held by scientists. We quote here from the article in the British daily newspaper The Guardian ( McKie, 2014):

"Climate change is no longer viewed as a future threat round here," says atmosphere expert Professor Ben Kirtman, of the University of Miami. "It is something that we are having to deal with today."..."Every year, with the coming of high spring and autumn tides, the sea surges up the Florida coast and hits the west side of Miami Beach, which lies on a long, thin island that runs north and south across the water from the city of Miami. The problem is particularly severe in autumn when winds often reach hurricane levels. Tidal surges are turned into walls of seawater that batter Miami Beach's west coast and sweep into the resort's storm drains, reversing the flow of water that normally comes down from the streets above. Instead seawater floods up into the gutters of Alton Road, the first main thoroughfare on the western side of Miami Beach, and pours into the street. Then the water surges across the rest of the island... Hence the construction work at Alton Road, where $\$ 400 \mathrm{~m}$ is now being spent in an attempt to halt these devastating floods by improving Miami Beach's stricken system of drains and sewers. In total, around $\$ 1.5 \mathrm{bn}$ is to be invested in projects aimed at holding back the rising waters. Few scientists believe the works will have a long-term effect.

What makes Miami exceptionally vulnerable to climate change is ... geology. The city - and its satellite towns and resorts - is built on a dome of porous limestone which is soaking up the rising seawater, slowly filling up the city's foundations and then bubbling up through drains and pipes. Sewage is being forced upwards and fresh water polluted. Miami's low topography only adds to these problems. There is little land ... that rises more than six feet above sea level. Many condos and apartment blocks open straight on the edge of the sea. Of the total of 4.2 million US citizens who live at an elevation of four feet or less, 2.4 million of them live in south Florida.

At Florida International University, geologist Peter Harlem has created a series of maps that chart what will happen as the sea continues to rise. These show that by the time oceans have risen by four feet - a fairly conservative forecast - most of Miami Beach, Key Biscayne, Virginia Key and all the area's other pieces of prime real estate, will be bathtubs. At six feet, Miami city's waterfront and the Florida Keys will have disappeared. The world's busiest 
cruise ship port, which handles four million passengers, will disappear beneath the waves. 'This is the fact of life about the ocean: it is very, very powerful,' says Harlem."

The other view - the other story - is held and offered by the politicians, who deny climate change and thus the possibility of its wiping out of the city. As The Guardian put it,

"Most of Florida's senior politicians - in particular, Senator Marco Rubio, former governor Jeb Bush and current governor Rick Scott, all Republican climate-change deniers - have refused to act or respond to warnings of people like Wanless or Harlem or to give media interviews to explain their stance, though Rubio, a Republican party star and a possible 2016 presidential contender, has made his views clear in speeches. 'I do not believe that human activity is causing these dramatic changes to our climate the way these scientists are portraying it. I do not believe that the laws that they propose we pass will do anything about it, except it will destroy our economy,' he said recently."

This more attractive description of the "resilience and unfettered economic growth and wellbeing" of Miami, which is offered by the politicians, appears to be holding sway over the calamity aesthetic of the story offered by the scientists - despite the scientific evidence and growing rate of flooding reported by the newspaper. So, according to The Guardian story:

"What really surprises visitors and observers is the city's response, or to be more accurate, its almost total lack of reaction. The local population is steadily increasing; land prices continue to surge; and building is progressing at a generous pace. During my visit last month, signs of construction - new shopping malls, cranes towering over new condominiums and scaffolding enclosing freshly built apartment blocks - could be seen across the city, its backers apparently oblivious of scientists' warnings that the foundations of their buildings may be awash very soon.”

This example illustrates how a judgment about plausibility or implausibility depends on the audience's response to the aesthetics of each story, and its alignment with the prevalent aesthetic. Here, one story offers a very attractive vision of a sunny retirement, the other a catastrophic future, comprising a soon-to-be ruined community and dashed hopes; one offers an aesthetic of hope and comfort, the other of desperation. The first aligns with the prevailing aesthetic of the community (and certainly of the politicians), while the other does not. The idea that Miami will disappear (and soon, too), with huge economic, societal, and possibly humanitarian crises ensuing, is hugely uncomfortable knowledge. As The Guardian put it, "Miami and its surroundings are facing a calamity worthy of the Old Testament." Moreover, in contrast to the Herodotean example, where making sense of Delphi's ambiguous message involved getting together and debating its meaning, in this modern example, no process of interactive sense-making is reported.

\section{Analysis}

Both examples, from past and present, reveal story-telling and -hearing as dynamic, creative and multi-dimensional processes that invite engagement not just (or not at all) with factuality, but with other kinds of knowledge. In each case, those judging the plausibility of what they hear do so on the basis of what feels "right", that is, according to their aesthetic understanding. We must emphasise that when we argue this, we are obviously drawing attention to aesthetics that are peculiar to a time and place, and not arguing that specific aesthetics are universal. 
The first example, from Herodotus reveals a multi-faceted role for aesthetics in a process of decision making. There were a variety of ways in which aesthetics were involved in an oracular consultation at Delphi, including the materiality and natural beauty of the location and the physical ritual of consultation, elements that were, arguably, involved in supporting the apparent authority that Delphi claimed. But, above all, oracular consultation involved a process of developing (alternative) stories about the future, and, as we have argued, the process of story-telling itself is an inherently aesthetic process. Our case study, which provides an example of a double oracular response, demonstrates how story-telling can be harnessed to create different options, the aesthetic of the story evoking feelings that a particular option may be plausible (or not), and therefore actionable (or not). Moreover, we may also see here the role of the relationality of aesthetics writ large: the final decision was one that was made in discussion with others, even, it could be said, in collaboration with supernatural forces (Eidinow, 2013). The Athenians developed their explanation of the oracle's response together in line with what felt right - in this case, their sense of Athenian identity. We should note that not everyone in the city agreed; a group of citizens opted for a different interpretation and stayed in Athens. However, they seem still to have shared in the same underlying aesthetic - it felt right to them to stay and fight. That their understanding manifested in a different response to the question of the plausibility of Themistocles' narrative could be taken to indicate that his manipulation of the aesthetic technology was only partially successful.

Our second example demonstrates how a story with an aesthetic that is too unappealing, too ugly, and too distant to be felt closely therefore exerts a weaker effect; it is not (yet) considered plausible. This may be because those involved have had no direct felt experience of what the story expresses or its implications (Weber, 2006), and without personal experience of what the story conveys, the vision of a climate change-infested future is simply too uncomfortable to be felt as plausible. This idea has been explored in terms of other manmade horrors, recently for example regarding the massive collective denial of the Indonesian massacre of about one million people ("eight times the combined death toll of Hiroshima and Nagasaki") by the perpetrators, now in power, as conveyed by Joshua Oppenheimer and analysed by Beatty (2015).

This raises the question of how to make plausible information that is not aesthetically appealing and which thus becomes "uncomfortable" (Coulson 1985, cited in Stein, 1988: 195). A story that is aesthetically attributed as ugly can still be considered intriguing and worth further study. In the field of strategic planning, this is important: engaging with aesthetically unappealing knowledge or questions may prompt the creation of "new connections that enable alternative perceptions to transcend such categories" (Ramírez, 2008). To do this new aesthetics are required, which may be achieved through the co-creation of stories. The process of reframing a future together encourages people to participate in creating the futures described in the stories. As the example from Herodotus illustrates, when stories are co-created for plausibility, this process can allow people to surface and to check their assumptions, to reveal the risks involved, to imagine options for action, to think through the possibilities, which might otherwise be missed. Shared stories are able to unite a community, playing a role in creating the sense of connection that comprises aesthetic knowledge. In contrast, stories that are not shared - perhaps because their aesthetics entail implausibility - do not build or sustain community; instead they manifest, and can even deepen, division.

\section{Conclusion}


This paper argues that the role of aesthetics in making stories plausible is a crucial one. The crafting of the "right" aesthetic in a story - one that appeals to or challenges an overriding aesthetic of a culture or community - is thus a significant factor in contexts of decision making. That this aspect has been largely overlooked is, we suggest, because it is so pervasive in everyday experience that its salience has been taken for granted. With this paper, we hope to draw attention to its role, suggesting that the aesthetics of story-making be regarded as a technology of the plausible.

Our two case studies offer examples of how powerful such a technology may be. They show how stories about possible futures do not just describe a future, they can also generate actions (or indeed, inactions) that contribute to it. Story-making, story-telling, and story-sharing achieve this, in part, by means of their aesthetics, which interact with other forms of sensory knowledge to enhance (or not) a sense of plausibility. This allows us to add to the description of Weick (1995, 60-1), when he argues that "A good story holds disparate elements together long enough to energize and guide action, plausibly enough to allow people to make retrospective sense of whatever happens, and engagingly enough that others will contribute their own inputs in the interest of sensemaking." We agree with this summary, but note that by adding the aesthetic aspect, we can begin to understand why stories may seem plausible, and, in turn, why they energise and guide, and, above all, may encourage individuals to engage and contribute. Thus, we propose that focusing on the aesthetics of stories as a technology to create and share plausibility is a useful way to analyse scenario stories in scenario-planning work; we hope that it may be a useful concept with which to develop further research in this area.

\section{References}

Beatty, A. (9/6/2015) Act of Killing sequel The Look of Silence unearths deeper truths about Indonesia's violent past, The Conversation: http://theconversation.com/act-of-killing-sequel-the-lookof-silence-unearths-deeper-truths-about-indonesias-violent-past-42975 accessed 22/6/2015.

Bosch, R. (2010) Objectivity and plausibility in the study of organizations. Journal of Management Inquiry, 19(4), 383-391.

Bourdieu, P. (1979) La distinction. Critique sociale du jugement. Paris : Les Editions de Minuit.

Bowden, H. (2005) Classical Athens and the Delphic oracle: Divination and democracy. Cambridge University Press, Cambridge.

Cassirer, E. (1964) Philosophie des symbolischen Formen, Darmstadt: Wissenschatliche

Buchgesellschaft.

Cheit, R. (Project director) (undated). Understanding the Iran-Contra Affairs.

https://www.brown.edu/Research/Understanding the Iran Contra Affair/e-

presidentialresponsibility.php accessed November 2015

Cornelissen, J. P. and Werner M.D. (2014) Putting framing in perspective: A review of framing and frame analysis across the management and organizational literature. The Academy of Management Annals, 8 (1), 81-235

Coulson, E. (1985) Using anthropology in a world on the move. Human Organization, 44(3), 191196.

Damasio, A. (2000) The feeling of what happens: body, emotion, and the making of consciousness.

New York: Vintage Books.

de Barrón, Í. (3/11/2013) Guindos expresa a la banca su 'malestar' con su nuevo presidente'

El País. http://economia.elpais.com/economia/2013/11/02/actualidad/1383419747 420688.html accessed on $2 / 11 / 14$ 
Eidinow, E. (2013) Oracular consultation, fate, and the concept of the individual. In V. Rosenberger (Ed.), Divination in the ancient. World: religious options and the individual, Steiner, Stuttgart (2013), pp. 21-39.

Eidinow, E. and Ramirez, R. (2012) "The Eye Of The Soul": Phronesis and the aesthetics of organizing. Organizational Aesthetics, 1 (1), 26-43.

Farmelo, G. (ed.) (2002) It must be beautiful great equations of modern science. London: Granta Books.

Feldman, S. P. (2000). Micro matters: the aesthetics of power in nasa's flight readiness review, The Journal of Applied Behavioural Science 36(4), 474-490.

Floyd, C. F. (1983). Billboards, aesthetics, and the police power. American Journal of Economics and Sociology 42(3), 369-382.

Gobster, P. H. (1999). An ecological aesthetic for forest landscape management. Landscape

Management 18(1), 54-64.

Hutchins, E. Cognition in the Wild. (1995). MIT Press.

Kay, J. (26/2/2013). A story can be more useful than maths. Financial Times.

http://www.ft.com/cms/s/0/b22182d4-7f49-11e2-97f6-00144feabdc0.html\#axzz3d77Icgox accessed 20/11/2015

Langer, S. (1942). Philosophy in a new key: a study in the symbolism of reason, right, and art. Cambridge, MA: Harvard University Press.

Lash, S. (1994). Reflexivity and its doubles: structure, aesthetics, community. In U. Beck, A.

Giddens, and S. Lash, (Eds.) Reflexive modernization - politics, tradition and aesthetics in the modern social order. London: Polity Press.

Latour, B. (1990). Technology is society made durable. The Sociological Review 38 (1): 103-131.

Maurizio, L. (1995) Anthropology and spirit possession: A reconsideration of the pythia's role at

Delphi, Journal of Hellenic Studies, 115, 69-86.

McKie, R. (11/07/2014). Miami, the great world city, is drowning while the powers that be look away. The Guardian on-line, accessed online June 232015.

http://www.theguardian.com/world/2014/jul/11/miami-drowning-climate-change-deniers-sea-levelsrising

Meckler, M. and Baillie, J. (2003). The truth about social construction in administrative science, Journal of Management Inquiry 12, 273-284.

Milojević, I and Inayatullah, S. (2015) Narrative foresight, Futures, 73, 151-162

Ramirez, R. (1987) Towards an aesthetic theory of social organisation. Doctoral dissertation, Social Systems Science Department, the Wharton School, University of Pennsylvania.

Ramirez, R. (1991) The beauty of social organisation. Accedo, Munich.

Ramirez, R. (1996) Wrapping form and organisational beauty, Organisation, 3 (2), 233-242

Ramirez, R. (2005) The aesthetics of cooperation, European Management Review, 2 (1), 28-35.

Ramirez, R. (2008) Scenarios providing clarity to address turbulence. In R. Ramírez, J. Selsky, K. van der Heijden (Eds.), Business planning in turbulent times: new methods for applying scenarios, Earthscan, London, 187-206.

Ramírez, R. and Arvidsson, N. (2005) The aesthetics of business innovation: an exploratory distinction of two archetypes. Innovation: Management, Policy, and Practice, 7 (4), 373-388.

Ramírez, R. and Selin, C. 2014. Plausibility and probability in scenario planning, Foresight, 16 (1), 54-74.

Raven, P. G. and Elahi, S. (2015) The New Narrative: Applying narratology to the shaping of futures outputs Futures, 74, 49-61.

Sandelands, L. E. (1998) Feeling and form in social life. Rowman \& Littlefield, Lanham, MD (1998)

Schlagg, P. (2002). The aesthetics of american law. Harvard Law Review 115, 1047-1119. 
Selin, C. and A. Pereira (2013) Pursuing plausibility. International Journal of Foresight and Innovation Policy, 9 (2/3/4) (2013), 93-109.

Selin, C. (2011) Negotiating plausibility: Intervening in the future of nanotechnology. Science and Engineering Ethics, 17 (4), 723-737

Sinclair, N. (2004). The roles of the aesthetic in mathematical inquiry, mathematical thinking and learning, 6 (3): 261-284.

Stein, H. F. (1988). Uncomfortable knowledge: An ethnographic clinical training model. Family Systems Medicine, 6(1): 117-128.

Strati, A. (1999). Organization and aesthetics. London: Sage.

Taylor, S. S. and Hansen, H. (2005) Finding form: Looking at the field of organizational aesthetics Journal of Management Studies, 42 (6), 1211-1232.

van der Heijden, K. (2005). Scenarios. The art of strategic conversation. 2nd ed. London and New York: Wiley.

Warhurst, C. et al. (2000). Aesthetic labour in interactive service work: some case study evidence from the "new" Glasgow, The Service Industries Journal, 20 (3), 1-18.

Weber, E. (2006). Experience-based and description-based perceptions of long-term risk: why global warming does not scare us (yet). Climatic Change, 77(1), 103-120.

Weick, K. (1995) Sensemaking in organizations. Sage, Thousand Oaks, CA

Wilkinson, A. (2009). Scenarios practices: in search of theory, Journal of Futures Studies, 13 (3): 107-114.

Wilkinson, A. and Ramírez, R. (2010) Canaries in the mind: exploring how the financial crisis impacts 21st century future-mindfulness Journal of Futures Studies, 14 (3), 45-60.

Wilkinson, A. and Ramirez, R. (2016) Strategic reframing: The Oxford scenario planning approach, Oxford University Press, Oxford. 